\title{
GMR
}

\section{Protective effect of necrostatin-1 on myocardial tissue in rats with acute myocardial infarction}

\author{
Y.R. Liu and H.M. Xu \\ Department of Geriatrics, Huaihe Hospital of Henan University, Kaifeng, China \\ Corresponding author: Y.R. Liu \\ E-mail: yuruliucn@163.com \\ Genet. Mol. Res. 15 (2): gmr. 15027298 \\ Received July 23, 2015 \\ Accepted December 23, 2015 \\ Published May 20, 2016 \\ DOI http://dx.doi.org/10.4238/gmr.15027298
}

\begin{abstract}
The aim of this study was to investigate the protective effect of necrostatin-1 on myocardial tissue of acute myocardial infarction (AMI) rats and to provide a basis for necrostatin-1 for the treatment of acute myocardial infarction. AMI rats (45) were established by ligating the anterior descending branch of the left coronary artery. The rats were randomly divided into the model group and necrostatin-1 low-dose and high-dose groups. The control group rats (15) underwent the sham operation. The rats in the necrostatin-1 low-dose and high-dose groups were injected with 1 and $4 \mathrm{mg} / \mathrm{kg}$ necrostatin- 1 , respectively, via the tail vein. The rats in the control and model groups were injected with isometric dimethyl sulfoxide, once daily, for 3 consecutive days. The levels of RIP1 and RIP3 mRNA and phosphorylated protein in the myocardial tissue of rats were detected by real time polymerase chain reaction and western blot. The myocardial infarct size was detected by tetrazolium chloride. Compared with that in the control group, the levels of RIP1 and RIP3 mRNA and phosphorylated protein significantly increased in the myocardial tissue of model group rats, necrostatin-1 low-dose group, and high-dose group. The levels of RIP1 and RIP3 mRNA and phosphorylated protein in the myocardial tissue of rats in the necrostatin-1 low-dose and high-dose groups decreased significantly compared with that in the model group $(\mathrm{P}<0.05)$. The levels of RIP1
\end{abstract}


and RIP3 mRNA in the myocardium of the high-dose group rats were significantly lower than those of the low-dose group rats $(\mathrm{P}<0.05)$. The myocardial infarct sizes significantly increased in model, lowdose, and high-dose group rats. The apoptotic level of myocardial cells significantly decreased in the low-dose group and high-dose group after treatment with necrostatin-1 but was still higher than that of the control group $(\mathrm{P}<0.05)$. In conclusion, necrostatin-1 can inhibit myocardial tissue apoptosis and necrosis in acute myocardial infarct rats and has a protective effect on myocardial tissue.

Key words: Necrostatin-1; Acute myocardial infarction; Cell apoptosis

\section{INTRODUCTION}

Acute myocardial infarction is a common clinical cardiovascular and cerebrovascular disease. The incidence is sudden and the mortality is high; therefore, it has become one of the major diseases leading to death of cardiovascular and cerebrovascular patients (DiNicolantonio et al., 2015; Fordjour et al., 2015). The pathological basis of acute myocardial infarction is that myocardial vascular blockage causes hypoxia and ischemia in myocardial tissue, marked apoptosis, and necrosis of myocardial tissue, eventually disrupting the function of myocardial cells (Malick et al., 2014; Luo et al., 2015). Myocardial cell apoptosis is reversible, but necrosis is not. Myocardial cell function is difficult to recover once necrosis occurs. Hence, myocardial necrosis needs to be inhibited in the early stages in order to preserve the function of myocardial tissue. The preliminary stage of cell necrosis is thought to represent a passive cell behavior. However, a large number of recent studies have confirmed that necrocytosis is also regulated by a gene, and necrosis is known as programmed cell necrosis (Christofferson and Yuan, 2010). It is a cysteine-aspartic acid-dependent programmed regulatory cell death type induced by death receptors. Programmed cell necrosis is mainly mediated by receptor interacting protein kinase 1 (RIP1), RIP3, and mixed series of protein kinase-like structure and protein (MLKL) (Degterev et al., 2005; Zhang et al., 2009; Rosenbaum et al., 2010). In recent years, a study showed that necrostatin-1 could significantly inhibit the kinase activity of RIP1, to block the pathway of programmed cell necrosis (You et al., 2008; Han et al., 2009). Based on this theory, effectively blocking programmed cell necrosis by necrostatin-1 may protect the myocardial tissue of acute myocardial infarction patients, delay myocardial cell necrosis, and provide time needed to save the functions of myocardial cells. Therefore, the protective mechanism of necrostatin-1 on myocardial cells in acute myocardial infarction rats was explored in this study. The results provide a theoretical basis for the treatment of acute myocardial infarction.

\section{MATERIAL AND METHODS}

\section{Acute myocardial infarction model in rats}

Healthy Sprague Dawley (SD) rats (SPF grade, 180-220 g) were purchased from Weitong Lihua Experimental Animal Co. Ltd., Beijing, China. Chloral hydrate solution (1 mL $100 \mathrm{~g} / \mathrm{L} \mathrm{10 \% )} \mathrm{was} \mathrm{intraperitoneally} \mathrm{injected} \mathrm{into} 45$ experimental rats. The rats were fixed on 
the experimental table in the supine position after being anesthetized. A $24 \mathrm{G}$ trochar hose was inserted into the trachea as tracheal intubation to assist with ventilation. An incision was made in the left of the median chest, and the tissues were separated layer by layer. A thoracotomy was performed along the fourth intercostal space. The pericardium was separated. The heart was exposed from the left coronary anterior descending branch. A 6.0 needle with a noninvasive thread was used to pass through the cardiac wall and ligate (if the color of myocardial tissue below the ligation became shallow, the ligation was successful). The heart was quickly placed back into the thoracic cavity. A thoracotomy was conducted on the rats in the sham operation group and the left coronary artery was not ligated. The 45 rats were randomly divided into the model group, low-dose group, and high-dose group. Then, $1 \mathrm{mg} / \mathrm{kg}$ necrostatin-1 (Selleckchem, Houston, TX, USA) was injected into the rats of the low-dose group via the tail vein. Then, $4 \mathrm{mg} / \mathrm{kg}$ necrostatin- 1 was injected into the rats of the high-dose group via the tail vein. Isometric phosphate buffered saline (PBS) was injected into the rats of the model group and control group via the tail vein. After treatment for $72 \mathrm{~h}$, the rats were executed. The heart tissue and blood were collected. This study was performed in strict accordance with the recommendations in the Guide for the Care and Use of Laboratory Animals of the National Institutes of Health Eighth Edition, 2010 (Bethesda, MD, USA). The animal use protocol has been reviewed and approved by the Institutional Animal Care and Use Committee (IACUC) of Huaihe Hospital of Henan University.

\section{RT-PCR}

Myocardial tissue $(0.1 \mathrm{~g})$ was removed from each rat and placed in a mortar. Liquid nitrogen was poured, ground, and dissolved in $1 \mathrm{~mL}$ Trizol (Invitrogen, Carlsbad, CA, USA), vortexed, and mixed. Chloroform $(200 \mu \mathrm{L})$ was added and the solution was thoroughly mixed. The sample was placed on ice for $15 \mathrm{~min}$. The fluid was stratified. The sample was centrifuged at $15,000 \mathrm{~g}$ for $15 \mathrm{~min}$. The supernatant was partially transferred to a new EP tube. The isometric isopropanol was added, vortexed, placed on ice to precipitate RNA, and centrifuged at 15,000 $\mathrm{g}$ for $10 \mathrm{~min}$. The supernatant was discarded. Precooled $75 \%$ ethanol was added to wash the precipitate twice. RNase-free water was added to dissolve the precipitate. The sample concentration was determined. RNA was transcribed into cDNA using the reverse transcription kit (TaKaRa, Dalian, China) to act as the template for PCR. According to the RIP1 and RIP3 mRNA sequences provided by GeneBank, the primers were designed as follows: RIP1-F: 5'-GGGTGTTCATCCATTCTC-3', RIP1-R: 5'-CCCAGCATCTTGTGTTTC-3'; RIP3-F： 5'-GTGGGATGATGACGACG-3'， RIP3-R: 5'-TACGACCAGAGGCATACAGG-3'; GAPDH-F: 5'-GCGGGAAATCGTGCGTGAC-3', GAPDH-R: 5'-CGTCATACTCCTGCTTGCTG-3'. The cDNA obtained by reverse transcription was diluted 1:200. The reaction system was prepared according to the following volumes $(20 \mu \mathrm{L}): 2 X$ SYBR Green universal qPCR Master Mix (Roche, Basel, Switzerland) $10 \mu \mathrm{L}$; cDNA template $8.8 \mu \mathrm{L}$, upstream/downstream primers $(10 \mu \mathrm{M}) 0.6 \mu \mathrm{L}$, respectively. Then, they were placed in the following reaction system for amplification: Reaction conditions: predegeneration: $94^{\circ} \mathrm{C}$ or $30 \mathrm{~s}$; degeneration: $94^{\circ} \mathrm{C}$ for $5 \mathrm{~s}$; annealing: $94^{\circ} \mathrm{C}$ for $30 \mathrm{~s}$; extension: $72^{\circ} \mathrm{C}$ for $40 \mathrm{~s} ; 35$ cycles, terminal extension for $5 \mathrm{~min}$ at $72^{\circ} \mathrm{C}$. The reaction was terminated, and the solubility curve was constructed. Finally, the data were read directly from the real-time fluorescence quantitative PCR instrument (Applied Biosystems, Foster City, CA, USA). 


\section{Western blot}

Myocardial tissue $(0.5 \mathrm{~g})$ from rats in each group was weighed and placed in a $1.5-\mathrm{mL}$ EP tube. Tissue lysate $(300 \mu \mathrm{L})$ was added. Then, the myocardial tissue was homogenized using the electric homogenate instrument. The sample was placed on ice for $20 \mathrm{~min}$ and centrifuged at $15,000 \mathrm{~g}$ for $10 \mathrm{~min}$. The supernatant was used to detect the total protein concentration using the BCA protein ELISA kit from Biyuntian Co., Shanghai, China. Loading buffer (5X) was added according to the sample volume and boiled in water for $10 \mathrm{~min}$. Sodium dodecyl sulfate polyacrylamide gel electrophoresis (SDS-PAGE) was conducted according to the amount of the total protein. When bromophenol blue ran to the edge, the electrophoresis was stopped and the protein on SDS-PAGE was transferred to a polyvinyl difluoride (PVDF) membrane. The PVDF membrane was incubated with 5\% skim milk powder for $30 \mathrm{~min}$, coated overnight with RIP1 and RIP3 rabbit polyclonal antibody (Abcam, Cambridge, UK) and GAPDH mouse monoclonal antibody (Abcam). The membrane was washed with PBS three times the next day (5 min/wash), labeled with HRP sheep anti rabbit secondary antibody (ZSGB-BIO, Beijing, China) at room temperature for $1 \mathrm{~h}$, and washed with PBS 3 times (5 min/wash). The sample was photographed and scanned after the illuminating agent was added.

\section{TTC staining}

After the rats in each group were executed, the hearts were quickly removed and washed with PBS. The atrium and the right ventricle were removed. The left ventricle was left intact, placed in $-20^{\circ} \mathrm{C}$ for $20 \mathrm{~min}$, and cut into sections with the freezing microtome. The thickness of each section was $2 \mathrm{~mm}$. The sections were placed in a preheated $37^{\circ} \mathrm{C}$ TTC staining solution and incubated at $37^{\circ} \mathrm{C}$ in the dark for $15 \mathrm{~min}$. The myocardial tissue was turned over for homogeneous dyeing and washed with PBS three times. At this time, the infarct area was white. The non-infarct area was deep red. The different staining areas were measured using image processing software. Myocardial infarct size $=$ (infarct size/myocardial area $\mathrm{x}$ myocardial weight of the section)/left ventricular weight $100 \mathrm{X}$.

\section{Statistical analysis}

All data were analyzed using SPSS 17.0 software (SPSS Inc., Chicago, IL, USA). The measurement data are reported as means $\pm \mathrm{SD}$. The enumeration data was analyzed using the chi-square test. The two-two comparison among groups was analyzed using the least significant difference method. $\mathrm{P}<0.05$ was considered statistically significant.

\section{RESULTS}

\section{Comparison of RIP3 and RIP1 mRNA levels in myocardial tissues of rats in each group}

The RIP3 and RIP1 mRNA primer specificities were satisfactory and there was good consistency in the amplification curves. Fluorescence quantitative PCR analysis results are shown in Figure 1. Compared with that in the control group, the levels of RIP1 and RIP3 
mRNA in the model group, low-dose group, and high-dose group rats significantly increased after the model was established. The difference was statistically significant $(\mathrm{P}<0.05)$. The levels of RIP1 and RIP3 mRNA significantly decreased in rats in the low-dose and high-dose groups after treatment with necrostatin-1 $(\mathrm{P}<0.05)$. Among them, the decrease in the highdose group was more significant than that of the low-dose group $(\mathrm{P}<0.05)$.

$\mathbf{A}$

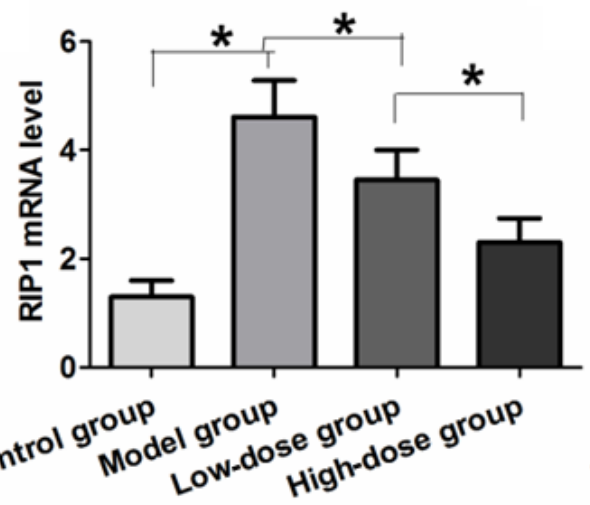

B

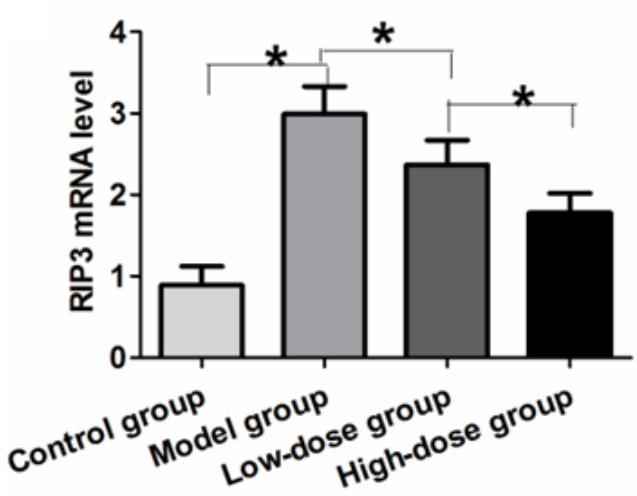

Figure 1. Comparison of RIP3 and RIP1 mRNA levels in myocardial tissue of rats from each group. A. Comparison of RIP1 mRNA in the heart tissue of four groups; B. Comparison of RIP3 mRNA in the heart tissue of four groups.

\section{Comparison of RIP1 and RIP3 protein levels in myocardial tissue of rats in each group}

The levels of phosphorylated RIP1 and RIP3 proteins increased significantly in the myocardial tissue of the model group, low-dose group, and high-dose group compared to that in the control group. The difference was statistically significant $(\mathrm{P}<0.05)$. After treatment with necrostatin-1, the levels of phosphorylated RIP1 and RIP3 proteins significantly decreased in the myocardial tissues of rats in the low-dose and high-dose groups $(\mathrm{P}<0.05)$ (Figure 2).

A

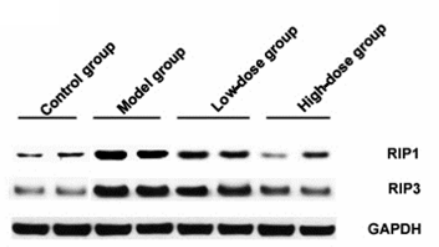

B

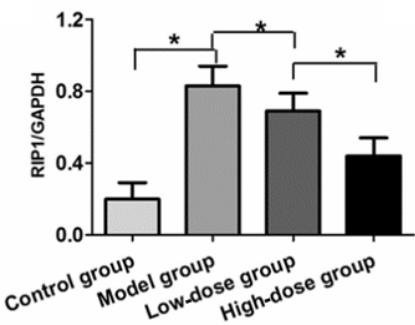

C

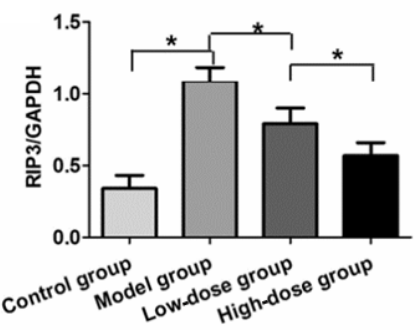

Figure 2. Comparison of RIP1 and RIP3 protein levels in myocardial tissue of rats from each group. A. Western blot showing the RIP1 and RIP3 protein expression in the heart tissue from the four groups; B. Quantitative analysis of RIP1 protein in the heart tissue of the four groups; C. Quantitative analysis of RIP3 protein in the heart tissue of the four groups. 


\section{Comparison of myocardial infarct size}

Compared with that in the control group, the myocardial infarct size increased significantly in the rats of the model group, low-dose group, and high-dose group. After treatment with necrostatin-1, the myocardial infarct size decreased significantly in the rats of the low-dose and high-dose group compared with the model group $(\mathrm{P}<0.05)$. The myocardial infarct size in the high-dose group significantly decreased compared to that of the low-dose group $(\mathrm{P}<0.05)$ (Figure 3$)$.

A

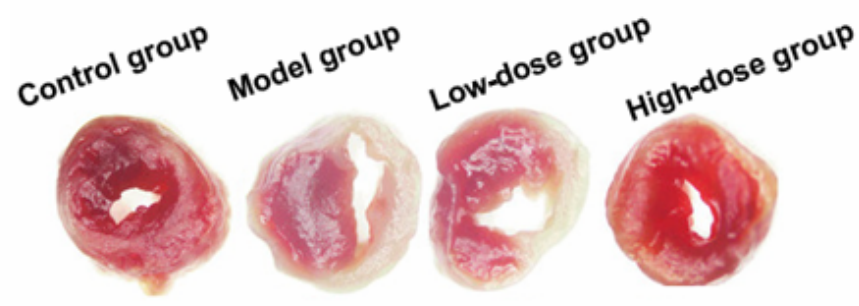

B

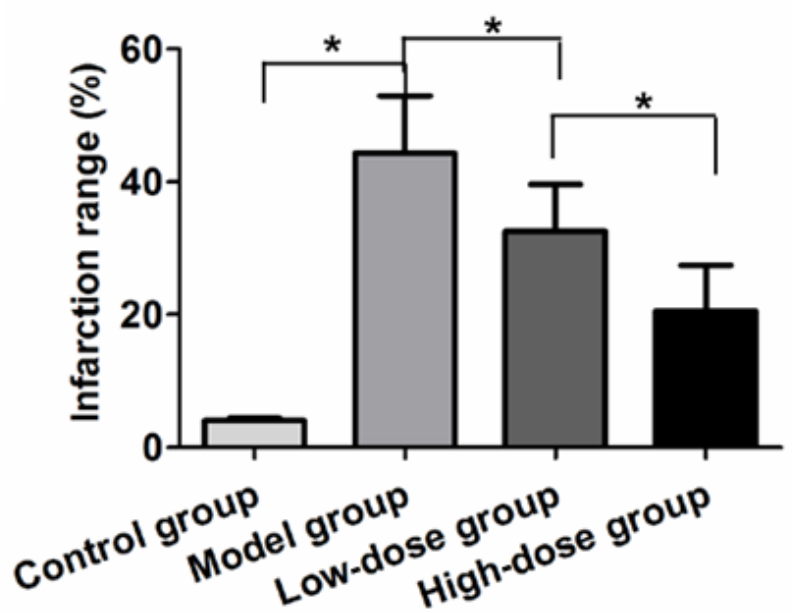

Figure 3. Comparison of myocardial infarct sizes in rats from each group. A. TTC showed myocardial infarct size of four groups (40X); B. Quantitative analysis of myocardial infarct size in four groups.

\section{DISCUSSION}

Acute myocardial infarction refers to acute myocardial ischemic necrosis. The coronary artery blood supply is drastically reduced or interrupted because of coronary artery lesions and the corresponding myocardium experiences persistent acute ischemia, resulting in myocardial necrosis. It is a severe type of coronary heart disease (Jeong et al., 2013; Jutla et al., 2014). The pathogenesis of acute myocardial infarction is characterized by plaque rupture hemorrhage, thrombosis, and a sharp decrease in coronary artery blood supply. This induces acute and persistent ischemia and hypoxia of the corresponding myocardium due to coronary atherosclerotic stenosis (Kivrak et al., 2014). The study showed that persistent 
myocardial ischemia and hypoxia caused myocardial cell apoptosis and necrosis. These two phenomena accompany the process of acute myocardial infarction. It is believed that apoptosis mainly occurs in the early stage of acute myocardial infarction and necrosis mainly occurs in the middle-late stage. Therefore, effectively inhibiting acute myocardial necrosis in acute myocardial infarction patients is important for saving myocardial cell function.

Cellular necrosis is considered a passive, disordered, and irreversible process. Programmed cell death consists of a series of ordered signal regulating processes triggered by death receptors such as tumor necrosis factor receptor (TNFR) and Fas and mediated by receptor interacting protein $1 / 3$ (RIPl/RIP3) kinase. It has the morphological features of necrotic cells, such as increased cell size, swelling organelles, and disrupted plasma membrane integrity (Galluzzi and Kroemer, 2008). Necrostatin-1 is a type of alkaloid that affects RIP3 and RIPl kinases by inducing a loss in kinase activity, inhibiting the phosphorylation of RIPl and RIP3, thereby inhibiting programmed cell necrosis (Xu et al., 2007; Xu et al., 2010). Therefore, the effect of necrostatin-1 on the myocardial tissue of acute myocardial infarction rats was analyzed in this study.

The results showed that the expression of RIP1 and RIP3 mRNA decreased significantly in the myocardial tissue of acute myocardial infarction rats after treatment with necrostatin-1. Necrostatin-1 can inhibit the phosphorylation of RIP1 and RIP3. The expression of phosphorylated RIPl and RIP3 proteins was analyzed by western blotting. The results showed that, compared with that in the model group, the levels of phosphorylated RIP1 and RIP3 proteins significantly decreased in rat myocardial tissue after treatment with necrostatin-1, suggesting that necrostatin-1 can not only decrease the levels of RIP1 and RIP3 mRNA, but can also effectively inhibit the phosphorylation of RIP1 and RIP3, which is consistent with the biological activity of necrostatin (He et al., 2009).

The most direct consequence of acute myocardial infarction is myocardial necrosis. Can necrostatin-1 significantly affect the myocardial infarct size in acute myocardial infarction rats? The curative effect of necrostatin-1 was analyzed by TTC staining. The results showed that a large area of white infarcted area occurred in the myocardial tissue of rats in the model group after TTC staining. After treatment with necrostatin-1, the size of the infarcted white area significantly decreased, suggesting that necrostatin- 1 can inhibit myocardial cell necrosis and protect myocardial cells from a larger area of infarction.

In conclusion, necrostatin-1 can decrease the expression of RIP1 and RIP3 mRNA and the phosphorylation of RIP1 and RIP3 mRNA protein, thereby inhibiting myocardial cell necrosis, reducing infarction area, and having a protective effect on myocardial cells.

\section{ACKNOWLEDGMENTS}

Research supported by the Department of Science and Technology of Henan Province (\#162102310075).

\section{REFERENCES}

Christofferson DE and Yuan J (2010). Necroptosis as an alternative form of programmed cell death. Curr. Opin. Cell Biol. 22: 263-268. http://dx.doi.org/10.1016/j.ceb.2009.12.003

Degterev A, Huang Z, Boyce M, Li Y, et al. (2005). Chemical inhibitor of nonapoptotic cell death with therapeutic potential for ischemic brain injury. Nat. Chem. Biol. 1: 112-119. http://dx.doi.org/10.1038/nchembio711 
DiNicolantonio JJ, Fares H, Niazi AK, Chatterjee S, et al. (2015). $\beta$-Blockers in hypertension, diabetes, heart failure and acute myocardial infarction: a review of the literature. Open Heart 2: e000230. http://dx.doi.org/10.1136/ openhrt-2014-000230

Fordjour PA, Wang Y, Shi Y, Agyemang K, et al. (2015). Possible mechanisms of C-reactive protein mediated acute myocardial infarction. Eur. J. Pharmacol. 760: 72-80. http://dx.doi.org/10.1016/j.ejphar.2015.04.010

Galluzzi L and Kroemer G (2008). Necroptosis: a specialized pathway of programmed necrosis. Cell 135: 1161-1163. http://dx.doi.org/10.1016/j.cell.2008.12.004

Han W, Xie J, Li L, Liu Z, et al. (2009). Necrostatin-1 reverts shikonin-induced necroptosis to apoptosis. Apoptosis 14: 674-686. http://dx.doi.org/10.1007/s10495-009-0334-x

He S, Wang L, Miao L, Wang T, et al. (2009). Receptor interacting protein kinase-3 determines cellular necrotic response to TNF-alpha. Cell 137: 1100-1111. http://dx.doi.org/10.1016/j.cell.2009.05.021

Jeong H, Yim HW, Cho Y, Park HJ, et al. (2013). The effect of rigorous study design in the research of autologous bone marrow-derived mononuclear cell transfer in patients with acute myocardial infarction. Stem Cell Res. Ther. 4: 82. http://dx.doi.org/10.1186/scrt233

Jutla SK, Yuyun MF, Quinn PA and Ng LL (2014). Plasma cortisol and prognosis of patients with acute myocardial infarction. J. Cardiovasc. Med. (Hagerstown) 15: 33-41. http://dx.doi.org/10.2459/JCM.0b013e328364100b

Kivrak T, Sunbul M, Durmus E, Dervisova R, et al. (2014). Acute myocardial infarction due to liquid nicotine in a young man. Ther. Adv. Cardiovasc. Dis. 8: 32-34. http://dx.doi.org/10.1177/1753944713515765

Luo KQ, Long HB and Xu BC (2015). Reduced apoptosis after acute myocardial infarction by simvastatin. Cell Biochem. Biophys. 71: 735-740. http://dx.doi.org/10.1007/s12013-014-0257-1

Malick M, Gilbert K, Barry M, Godbout R, et al. (2014). Desvenlafaxine reduces apoptosis in amygdala after myocardial infarction. Brain Res. Bull. 109: 158-163. http://dx.doi.org/10.1016/j.brainresbull.2014.10.012

Rosenbaum DM, Degterev A, David J, Rosenbaum PS, et al. (2010). Necroptosis, a novel form of caspase-independent cell death, contributes to neuronal damage in a retinal ischemia-reperfusion injury model. J. Neurosci. Res. 88: $1569-1576$

Xu X, Chua CC, Kong J, Kostrzewa RM, et al. (2007). Necrostatin-1 protects against glutamate-induced glutathione depletion and caspase-independent cell death in HT-22 cells. J. Neurochem. 103: 2004-2014. http://dx.doi. org/10.1111/j.1471-4159.2007.04884.x

$\mathrm{Xu}$ X, Chua KW, Chua CC, Liu CF, et al. (2010). Synergistic protective effects of humanin and necrostatin-1 on hypoxia and ischemia/reperfusion injury. Brain Res. 1355: 189-194. http://dx.doi.org/10.1016/j.brainres.2010.07.080

You Z, Savitz SI, Yang J, Degterev A, et al. (2008). Necrostatin-1 reduces histopathology and improves functional outcome after controlled cortical impact in mice. J. Cereb. Blood Flow Metab. 28: 1564-1573. http://dx.doi.org/10.1038/ jebfm.2008.44

Zhang DW, Shao J, Lin J, Zhang N, et al. (2009). RIP3, an energy metabolism regulator that switches TNF-induced cell death from apoptosis to necrosis. Science 325: 332-336. http://dx.doi.org/10.1126/science.1172308 